\title{
BMJ Open Colorectal cancer in adolescents and young adults with Lynch syndrome: a Danish register-based study
}

\author{
Jon Ambæk Durhuus (D) , ${ }^{1}$ Christina Therkildsen, ${ }^{1,2}$ Thomas Kallemose, ${ }^{1}$ \\ Mef Nilbert ${ }^{1,3}$
}

To cite: Durhuus JA, Therkildsen C, Kallemose T, et al. Colorectal cancer in adolescents and young adults with Lynch syndrome: a Danish register-based study. BMJ Open 2021;11:e053538. doi:10.1136/ bmjopen-2021-053538

- Prepublication history and additional supplemental material for this paper are available online. To view these files, please visit the journal online (http://dx.doi.org/10.1136/ bmjopen-2021-053538).

Received 25 May 2021 Accepted 16 November 2021

\section{A) Check for updates}

(C) Author(s) (or their employer(s)) 2021. Re-use permitted under CC BY-NC. No commercial re-use. See rights and permissions. Published by BMJ.

${ }^{1}$ Department of Clinical Research, Copenhagen University Hospital - Amager and Hvidovre, Copenhagen, Denmark ${ }^{2}$ The Danish HNPCC Register, Gastro Unit, Copenhagen University Hospital - Amager and Hvidovre, Copenhagen, Denmark

${ }^{3}$ Danish Cancer Society

Research Center, Copenhagen, Denmark

Correspondence to Dr Jon Ambæk Durhuus; jon.durhuus@regionh.dk

\section{ABSTRACT}

Objective To assess clinicopathological predictors and prognosis in early-onset colorectal cancer (CRC) in Lynch syndrome with comparison to patients diagnosed from age 40 and up.

Design National, retrospective register-based casecontrol study.

Setting Danish national hereditary CRC register.

Participants Individuals with Lynch syndrome diagnosed with CRC from January 1950 to June 2020. The analysis was based on 215 early-onset CRCs diagnosed between 15 and 39 years of age and 574 CRCs diagnosed at age 40-88 years.

Main outcome measures Clinical and histopathological characteristics and survival. Confounding variables were analysed by Cox analysis.

Results $27.2 \%$ of the tumours in the Danish Lynch syndrome cohort were diagnosed under age 40 . Diseasepredisposing alterations in $\mathrm{MLH} 1$ and $M S H 2$ were overrepresented in the age 15-39 cohort compared with patients diagnosed over age 40. CRCs diagnosed under age 40 showed an adverse stage distribution with $36.2 \%$ stage III-IV tumours compared with $25.8 \%$ in the over age 40 group. However, young patients diagnosed with earlystage tumours did have a significantly better prognosis compared with early-stage tumours in the older age group. Conclusions Early-onset CRC in Lynch syndrome is primarily linked to alterations in $M L H 1$ and $M S H 2$ and displays an adverse stage distribution. These observations serve as a reminder of surveillance, symptom awareness and rapid diagnostic handling of CRC in young adults with Lynch syndrome.

\section{INTRODUCTION}

Colorectal cancer (CRC) incidence shows divergent trends in various age groups. In many western countries, the incidence of CRC above age 50 is decreasing, which has been attributed to the introduction of population-based screening. ${ }^{1}$ At the same time, incidence rates under age 50 annually increase by $1 \%-3 \%$ with particularly worrying rates in the youngest age group from age 18 to 40 years. ${ }^{2-12}$ In $2010,5 \%$ of colon cancers and $9 \%$ of rectal cancers were diagnosed under age 50. Due to these increasing

\section{Strengths and limitations of this study}

Data from a nation-wide Lynch syndrome register were used for comparison between early-onset and late-onset cases in a genetically predisposed population.

- Access to detailed clinicopathological data in a large study cohort allows for adjustment for factors such as sex, gene variant, tumour location and tumour stage.

- Incomplete data on surveillance colonoscopies prevent analyses of route to diagnosis.

- Long study timespan implies that risk factors, surveillance, diagnostics and treatment have changed during study time.

incidences it has been estimated that $11 \%$ of colon cancers and $22 \%$ of rectal cancers will be diagnosed under age 50 by 2030 with the largest estimated increase in the age group 20-34 years. ${ }^{8} 13$ However, paediatric CRC is rare with an estimated frequency under 1 per 1000000 cases. $^{6}$

Young age at onset is a hallmark of hereditary cancer, and at least $20 \%$ of the CRC cases are estimated to show familial patterns, and $5 \%$ carry disease-predisposing genetic variants. ${ }^{14-16}$ Under age $35-40$ years, up to onethird of the cases have been reported to be linked to hereditary syndromes, such as Lynch syndrome. ${ }^{16-19}$ Lynch syndrome is caused by disease-predisposing genetic variants in the mismatch-repair (MMR) genes MLH1, MSH2, MSH6 and PMS2 and represents the most common cause of hereditary CRC. Individuals with Lynch syndrome have $40 \%-70 \%$ risk of CRC with a mean age at first diagnosis of $40-45$ years, and $40 \%$ of the tumours are diagnosed under age $40 .{ }^{820-22}$ The increased life-time risk of CRC motivates surveillance colonoscopies, which typically include biennial examinations from age 25 years. ${ }^{23} 24$ Rational design of surveillance programmes is challenged by variable age at onset and risk 
of cancer within families, which calls for increased knowledge of predictors and characteristics of CRC under age 40 in individuals with Lynch syndrome. ${ }^{25}$

In individuals under age 40, symptoms of CRC tend to be unspecific. Furthermore, the disease is not a first-hand diagnostic consideration, which may explain observed diagnostic delays in this group. Patients with CRC under age 40 show a predilection for tumours in the descending colon and the rectum, an over-representation of signetring cell histology, mucinous and poor differentiation, more advanced stage at diagnosis and higher mortality rates. ${ }^{5} 912$ 26-28 The clinicopathological characteristics in the early-onset group suggest distinct routes of tumour development, though the molecular underpinnings remain to be defined. Data on early-onset CRC in Lynch syndrome are scarce and better knowledge in this field could support risk-adapted surveillance. ${ }^{29}$ Motivated by the alarming increase in incidence of sporadic CRC under age 40 , we defined this age as cut-off for early-onset CRC in Lynch syndrome. This also fits well with a mean age at diagnoses just above 40 in individuals with Lynch syndrome who do not undergo surveillance. We aimed to define predictors of early-onset CRC in Lynch syndrome, as well as clinicopathological characteristics and prognosis based on a national Lynch syndrome cohort.

\section{METHODS}

\section{Study population and data extraction}

This retrospective register-based case-control study was based on the national Danish Hereditary Non-polyposis Colorectal Cancer (HNPCC) register. The register contains more than 80000 individuals with a suspected or verified risk of familial or hereditary CRC..$^{30}$ All individuals with disease-predisposing MMR gene alterations were eligible for the study, which defined a cohort of 520 families in which all diagnoses were verified based on clinical charts and/or histopathology reports. We considered the first primary CRC and defined the early-onset group as CRC cases diagnosed under age 40. Two hundred and fifteen cases aged 15-39 years where found and the clinicopathological findings and survival of these groups were compared with the remaining cases diagnosed at 40-88 years of age.

Clinical data were extracted from the Danish HNPCC register on 11 June 2020 and the following variables were retrieved: MMR gene alteration (in the genes MLH1, MSH2, MSH6, PMS2 and EPCAM), sex, date of birth, date of death, documentation for diagnostics, date of diagnosis, tumour morphology, stage and location. EPCAM alterations can cause inactivation of the downstream MSH2 gene $^{31}$ and were pooled with $\mathrm{MSH} 2$ variants. The reported TNM classification was translated into clinical stage with analysis of tumour stage as well as clinical stage. Stage I included T1-T2, N0 and M0 tumours. Stage II consisted of T3-T4, N0 and M0. Stage III was T1-T4, N1-2 and M0, and stage IV included any T, any N and M1. Likewise, reports of tumours located in the ascending
1045 individuals with Lynch syndrome and CRC assessed with eligibility from the Danish HNPCC register

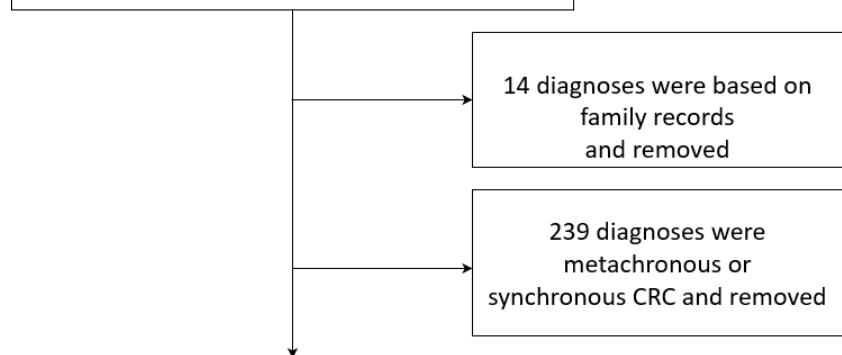

792 individuals with first diagnosed CRC

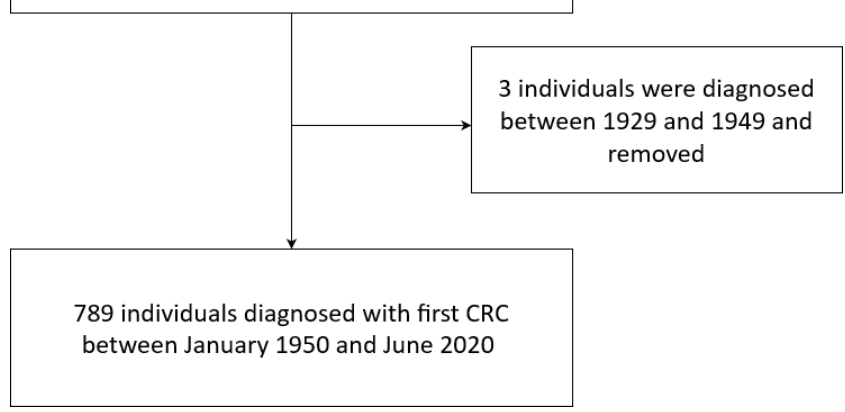

Figure 1 Flowchart of the study population. CRC, colorectal cancer; HNPCC, Hereditary Non-polyposis Colorectal Cancer.

colon, cecum, hepatic flexure and transverse colon were altogether analysed as proximal tumours, whereas reported tumours in the sigmoid colon, splenic flexure and descending colon were considered distal tumours.

Diagnoses based only on family history $(\mathrm{n}=14)$ and metachronous/synchronous tumours $(\mathrm{n}=239)$ were excluded. Furthermore, diagnoses before 1950 were removed $(n=3)$, leaving 789 eligible individuals for the study (figure 1). We would like to note that register studies are not subjected to ethical review according to Danish regulations. Furthermore, the manuscript has been written in accordance with the Strengthening the Reporting of Observational Studies in Epidemiology reporting guidelines. ${ }^{32}$

\section{Patient and public involvement}

Public and patient involvement was planned through the Danish HNPCC register that arranges annual patient information events and presents ongoing research projects on its web page.

\section{Statistical analysis}

Clinicopathological characteristics in the two study groups were initially analysed by univariate methods. Categorical variables in the two cohorts were analysed using $\chi^{2}$ test and differences within continuous variables were evaluated for normality assumption and calculated using Student's t-test. Five-year survival probabilities were visualised using the Kaplan-Meier method and differences between the two cohorts were estimated adjusted 
for stage by Kaplan-Meier estimator and tested by using log-rank test. Variables that were found to be statistically significant were further analysed. Adjusted estimates were presented as hazard ratios (HR) from Cox proportional hazard models and tested by Wald test. Possible confounding factors for the Cox model included MMR gene and tumour stage. The proportion of CRC under age 40 years in the total cohort $(n=789)$ was stratified by year of diagnostics and the ratio of CRCs diagnosed under versus over age 40 per decade is shown in a bar plot to illustrate possible time-dependent incidence. All statistical analyses were conducted using $\mathrm{R}$ ( $\mathrm{R}$ Core Team (2019) V.3.6.1. R: A language and environment for statistical computing. R Foundation for Statistical Computing, Vienna, Austria) using the ggplot ${ }^{33}$ and survival ${ }^{34}$ packages. All $\mathrm{p}$ values were two-sided and statistical significance was reached at $<0.05$.

\section{RESULTS}

In the total Danish Lynch syndrome cohort, the first CRC was considered in patients diagnosed after year 1950 $(\mathrm{N}=789)$. The total cohort contained 447 males $(56.7 \%)$ and 342 females $(43.3 \%)$ from 418 different families aged $15-88$ years with a mean age at diagnosis of 48.9 years. In total, $51.7 \%$ of the CRCs were diagnosed under age $50,27.2 \%$ under age $40,5.6 \%$ under age $30 \%$ and $1.8 \%$ under age 25 . The majority $(59.1 \%)$ of the tumours were located in the proximal colon. Disease-predisposing gene alterations in the cohort affected $M L H 1$ in $33.0 \%$, MSH2 in $39.4 \%$, MSH6 in $22.2 \%$ and PMS2 in $5.4 \%$ (table 1).

Due to incomplete data, further analyses related to histopathological subtypes were not performed. Moreover, inadequate data were available to test if the proportion of CRC were diagnosed during surveillance more often in the 40-88 age group than in the group under age 40 .

\begin{tabular}{|c|c|c|c|c|}
\hline Age (years) & Total & 15-39 & $40-88$ & $P$ value \\
\hline \multicolumn{5}{|l|}{ Characteristics } \\
\hline Families/individuals & $418 / 789$ & $149 / 215$ & $350 / 574$ & N/A \\
\hline Sex, male (\%) & $447(56.7)$ & $124(57.7)$ & $323(56.3)$ & $p=0.785$ \\
\hline Age at diagnosis, mean (range) & $48.9(15-88)$ & $33.1(15-39)$ & $54.8(40-88)$ & N/A \\
\hline Year of diagnosis, mean (range) & 2001 (1951-2020) & 1996.5 (1953-2019) & 2002.6 (1951-2020) & N/A \\
\hline Age at death, mean (range) & $59.5(25.3-96.9)$ & $47.3(25.3-89.1)$ & $64.3(41.0-96.9)$ & $\mathrm{p}<0.001^{*}$ \\
\hline Mean survival in years (range) & $12.3(0-55.7)$ & $15.8(0-55.7)$ & $11.0(0-42.1)$ & $p<0.001^{*}$ \\
\hline Disease-predisposing gene & n (\%) & $\mathrm{n}(\%)$ & $\mathrm{n}(\%)$ & $p<0.001$ \\
\hline MLH1 & $260(33.0)$ & $92(42.8)$ & $168(29.3)$ & \\
\hline MSH2 & $311(39.4)$ & $97(45.1)$ & $214(37.3)$ & \\
\hline MSH6 & $175(22.2)$ & $20(9.3)$ & $155(27.0)$ & \\
\hline PMS2 & $43(5.4)$ & $6(2.8)$ & $37(6.4)$ & \\
\hline Tumour location & & & & $p=0.734$ \\
\hline Proximal colon & $443(59.1)$ & $116(56.6)$ & $327(60.0)$ & \\
\hline Distal colon & $184(24.6)$ & $53(26.3)$ & $131(24.0)$ & \\
\hline Rectum & $122(16.3)$ & 35 (17.1) & 87 (16.1) & \\
\hline Clinical stage & & & & $p=0.006$ \\
\hline I & $132(19.4)$ & 24 (13.3) & $108(21.6)$ & \\
\hline II & $355(52.1)$ & $91(50.6)$ & $264(52.7)$ & \\
\hline III & $150(22.0)$ & $46(25.6)$ & $104(20.8)$ & \\
\hline IV & $44(6.4)$ & 19 (10.6) & $25(5.0)$ & \\
\hline Tumour stage & & & & $p=0.006$ \\
\hline $\mathrm{T} 1$ & $44(7.4)$ & $10(6.9)$ & $34(7.5)$ & \\
\hline T2 & $93(15.6)$ & 17 (11.7) & 76 (16.9) & \\
\hline T3 & 247 (41.4) & 49 (33.8) & 198 (43.9) & \\
\hline T4 & 212 (35.6) & 69 (47.6) & $143(31.7)$ & \\
\hline
\end{tabular}

Characteristics for the total cohort. Distribution and $p$ values between under age 40 and above age 40 for characteristics, diseasepredisposing gene, tumour location, clinical stage and tumour stage.

*Student's t-test.

NA, not applicable. 
Age distribution in relation to disease-predisposing MMR gene, tumour location within the bowel and tumour stage are presented in online supplemental figure S1.

Comparison between CRCs diagnosed under age 40 versus over age 40 using univariate analysis considered age at diagnosis, age at death, survival in years, sex, MMR gene alteration, tumour location, clinical stage and tumour stage (table 1). The early-onset cases $(\mathrm{N}=215)$ were diagnosed at age $15-39$ years, and the over age 40 cases $(\mathrm{N}=574)$ were diagnosed at age $40-88$ years. Mean age at death was 47.3 years in the age 15-39 cohort versus 64.3 in the over age 40 cohort, whereas mean survival was 15.8 years in the age 15-39 group and 11.0 years in the over age 40 group. The differences in age of death and survival could be influenced by differences in life expectancy between these cohorts. Disease-predisposing alterations in the MMR genes MLH1 (42.8\% vs $29.3 \%)$ and $M S H 2(45.1 \%$ vs $37.3 \%$ ) were overrepresented in the age 15-39 group, whereas $M S H 6$ alterations were overrepresented among individuals diagnosed from age 40 and up $(27.0 \%$ vs $9.3 \%)(p<0.001)$. CRCs diagnosed from age 15 to 39 were associated with an adverse stage distribution with more advanced clinical tumour stage (stage III and IV, $\mathrm{p}=0.006)$ as well as a higher tumour stage $\mathrm{T} 4(\mathrm{p}=0.006)$. Sex and tumour location did not significantly differ between the two cohorts (table 1 ).

The unadjusted 5-year survival analysis did not reveal differences between the groups with a 5-year overall survival probability of $82 \%$ (unadjusted log-rank $\mathrm{p}=0.86$ ) in both groups (online supplemental figure 2). Factors that showed significant correlation in univariate analyses, that is, disease-predisposing gene and clinical stage, were included in the adjusted multivariate Cox model. Tumour stage was not included due to its interaction with clinical stage. Age group and disease-predisposing gene(s) were not significantly associated with overall survival, whereas clinical stage did predict an increased risk for death as expected with HRs of 5.06 for clinical stage III and 28.1 for clinical stage IV (table 2).

Next, we investigated differences in 5-year survival in the two age groups stratified for clinical tumour stage (online supplemental figure 3A-D). There was an increased probability of 5-year overall survival in the 15-39 age group with tumour stage II (online supplemental figure 3A) $(\mathrm{p}=0.03)$. Differences in survival between the age groups in tumour stage I, III and IV were insignificant and in some cases, such as stage IV, the numbers were quite low (online supplemental figure 3D). Therefore, we chose to analyse early-stage and late-stage between the age groups, where stage I and II were classified as early-stage (I+II) and stage III and IV as late-stage (III+IV) (figure 2). After adjustment for tumour stage, 5-year overall survival in early-stage tumours was $97 \%$ in the age 15-39 group and $90 \%$ in the group diagnosed over age $40(\mathrm{p}=0.017)$. The corresponding figures in late-stage tumours were $55 \%$ in the age 15-39 group and $65 \%$ in the group above age 40 $(\mathrm{p}=0.27)$.
Table 2 HRs for 5-year overall survival in the colorectal cancer Lynch syndrome cohort

\begin{tabular}{lllc}
\hline Characteristics & HR & $95 \%$ Cl & P value \\
\hline Age of onset & & & \\
40-88 years (reference) & - & - & \\
15-39 years & 0.90 & 0.64 to 1.28 & 0.6 \\
\hline Clinical stage & & & \\
\hline Stage I (reference) & - & - & \\
\hline Stage II & 1.94 & 0.86 to 4.36 & 0.11 \\
\hline Stage III & 5.06 & 2.25 to 11.4 & $<0.001$ \\
\hline Stage IV & 28.1 & 12.3 to 64.3 & $<0.001$ \\
\hline Unknown & 10.2 & 4.57 to 22.6 & $<0.001$ \\
\hline Disease-predisposing gene & & & \\
\hline PMS2 (reference) & - & - & \\
\hline MLH1 & 1.23 & 0.53 to 2.86 & 0.6 \\
\hline MSH2 & 0.97 & 0.42 to 2.26 & $>0.9$ \\
\hline MSH6 & 1.39 & 0.58 to 3.33 & 0.5 \\
\hline
\end{tabular}

$\mathrm{HR}, 95 \% \mathrm{Cl}$ and $\mathrm{p}$ value for age of onset (of first colorectal cancer), age of diagnosis, clinical stage, disease-predisposing gene and tumour stage.

In the data set from the national Danish HNPCC registry we could follow the age distribution at diagnosis of the first CRC over time (figure 3A, B). The frequency of CRCs diagnosed per decade increased in both age groups (figure 3A). However, the largest increase in numbers was observed in the group above age 40 . Reported diagnoses per decade remained relatively constant in the group under age 40 during the time period 1950-1989, whereas the incidences doubled during the period 19902019 (figure 3A). The proportion of the two groups per decade, shows that the older group starts as the minor group, and ends up comprising $80 \%$ of diagnosed CRC in the last decade (figure 3B). The increasing number of diagnosed CRCs is influenced by an expanding number of identified Lynch syndrome families and due to surveillance programmes that have gradually been introduced for individuals with increased risk of CRC. Thus, these data need to be interpreted with caution. Our data do, however, not support an increasing proportion of CRCs in the age 15-39 group over time in the Danish Lynch syndrome cohort.

Among adolescents and young adults under age 25 we observed 14 CRCs, of which 6 were diagnosed under age 20. Clinicopathological data from these cases are summarised in online supplemental table 1 . Of the 14 CRCs under age 25, data on diagnostic path were available from 9 cases, of whom 8 were diagnosed due to symptoms. Two of these individuals had concurrent ulcerative colitis, which motivated colonoscopy in the only individual diagnosed through surveillance. This subset showed a predominance for advanced $\mathrm{T}$ stages with $28.6 \% \mathrm{~T} 3$ and $28.6 \% \mathrm{~T} 4$ tumours, though still with a predominance for 


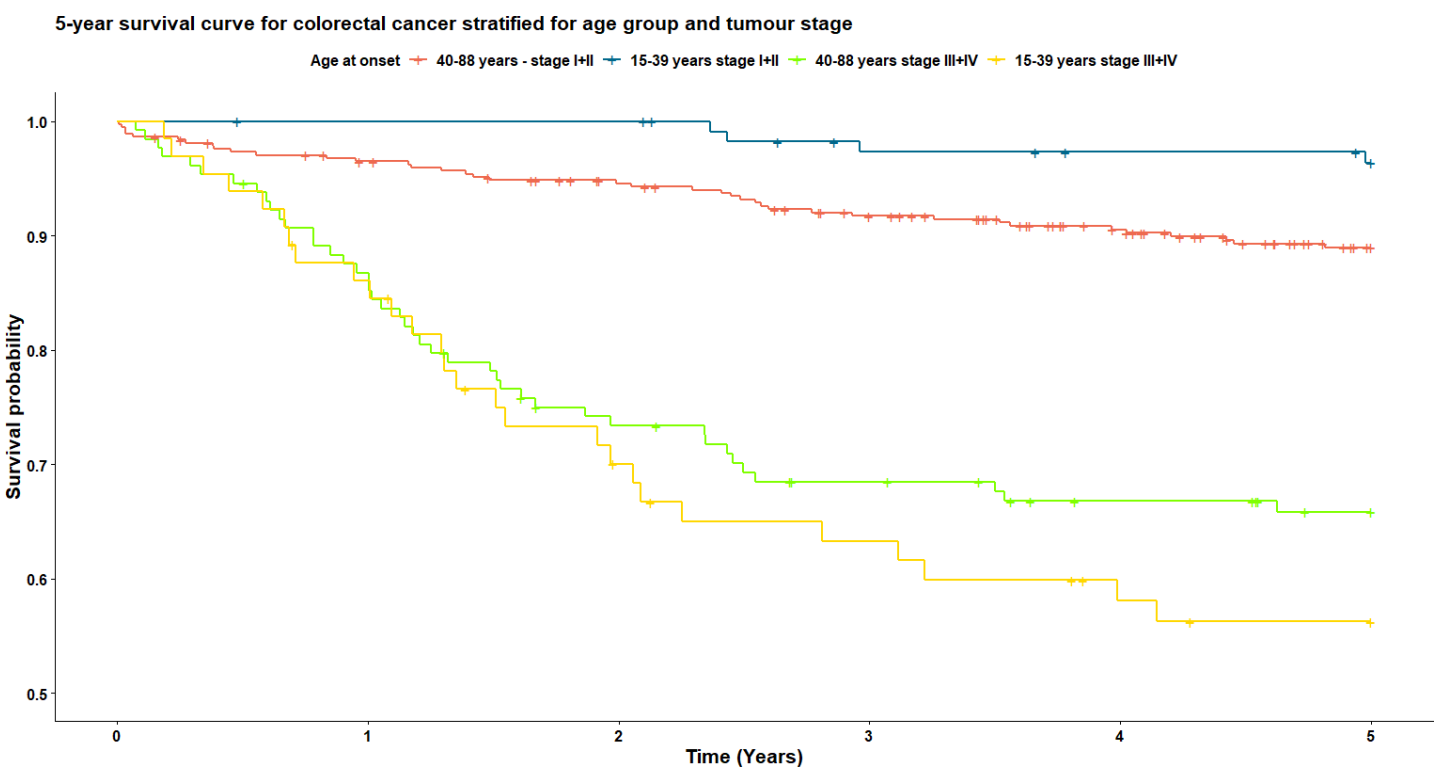

Figure 2 Five-year survival curve for colorectal cancer adjusted for age group and tumour stage. Flve-year survival probability in the early-onset group (age 15-39 years) and the late-onset group (age 40-88 years) stratified by clinical tumour stage I-II and stage III-IV.

clinical stage II (50.0\%) and few stage III-IV tumours (online supplemental table 1).

\section{DISCUSSION}

Based on the national Danish Lynch syndrome cohort, we demonstrate that early-onset CRC, defined as tumours under age 40 (15-39 years), is largely driven by diseasepredisposing variants in $M L H 1$ and $M S H 2$ and show a dismal clinicopathological profile with an overrepresentation of advanced tumours (T4 and stage III-IV tumours). In this age group, $36.2 \%$ of the patients were diagnosed with stage III-IV tumours compared with $25.8 \%$ in the group above age 40. Among patients diagnosed with earlystage tumours, the age 15-39 group showed significantly better survival whereas no significant difference applied to late-stage tumours. However, the over-representation of late-stage tumours in the age 15-39 group with an overall 5-year survival of 55\% calls for increased awareness to support early diagnostics and thereby improved outcomes.

Our population approach with data from 215 CRC cases in the age 15-39 group and 574 CRCs diagnosed at age 40 and up, provides a robust sample size. Nevertheless, the retrospective cohort design over a long time period could introduce ascertainment bias based on more distinguishing phenotypes in the earlier years. This was indeed observed in the higher percentage of early-onset cases in the early decades (figure 3A-B). This would imply that early-onset cases may have been more frequent in the early study period and may more often represent index cases with a tendency for more advanced tumour stage. Bias may also relate to TNM stages since pathology record

\section{B}

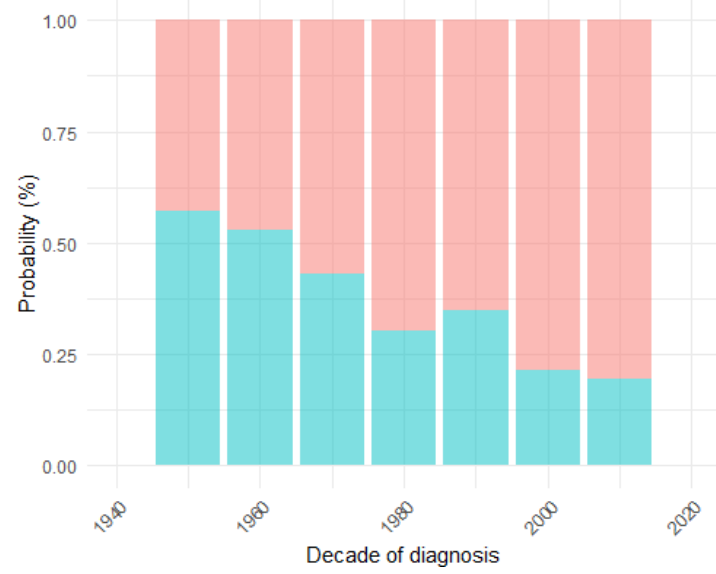

Figure 3 Frequency and proportion of early-onset colorectal cancers from 1950 to 2019. Frequency (A) and proportion (B) of diagnosed colorectal cancers in Lynch syndrome patients diagnosed under age 40 (blue) and above age 40 (orange). Diagnosed cases are represented per decade from 1950 to 2019, where each decade are depicted as 1950-1959, 1960-1969 and so on. 
from the first half of the study period used the Dukes classification and generally had a lower number of lymph nodes identified and evaluated, which implies a less precise conversion into TNM stages. Furthermore, we did not have access to complete information on surveillance colonoscopies, which implies that we could not correct for route of diagnosis, that is, symptomatic versus during surveillance.

Compared with sporadic CRC, tumours linked to Lynch syndrome have been demonstrated to have a favourable prognosis with survival probabilities above $80 \%$ after 10 years for stage I-III tumours, which has been linked to growth patterns with strong immune reactions and a lower risk of nodal spread. ${ }^{35}$ We verify an excellent prognosis for stage I-II tumours with 5-year survival rates of $97 \%$ in the age $15-39$ cohort and $90 \%$ in the above age 40 cohort. However, among patients diagnosed under age $40,36.2 \%$ were clinical stage III-IV at diagnosis with $81.4 \%$ of the tumours being T3-T4. Whether this reflects particularly early and aggressive tumour development in these patients, suboptimal compliance to surveillance or insufficient surveillance procedures as regards to quality or colonoscopy, surveillance intervals or other factors, remains unknown. Risk modifying factors such as the specific MMR gene defects, genetic modifiers, lifestyle factors and inflammatory processes, may influence the individual risk. The observation that adolescents, young adults and patients up to age 40 frequently present with large and late-stage tumours calls for attention to surveillance procedures, adherence and potential risk factor reduction in this patient group. ${ }^{36}$ For late-stage tumours, 5 -year survival rates were not significantly different at $55 \%$ in the early-onset group and $65 \%$ in the late-onset group. These figures support observations of an adverse prognosis in adolescents and young adults with nonhereditary CRC where prolonged diagnostic processes, adverse risk factor profiles and an overrepresentation of advanced disease stages have been documented. ${ }^{6}{ }^{11}$ On the other hand, the significantly better outcomes with 97\% 5-year survival for young patients with early-stage disease motivates early diagnostics in genetically predisposed individuals.

In Denmark, colonoscopic surveillance in Lynch syndrome is initiated from age 25, which implies that cases under this age were symptomatic, except for occasional patients surveilled due to intercurrent inflammatory bowel disease. Our study confirms that in Lynch syndrome the risk of developing CRC under age 40 is driven by disease-predisposing alterations in MLH1 and $\mathrm{MSH} 2$, which supports risk-adapted surveillance from age 25 in $M L H 1$ and $M S H 2$ carriers and from age 30 years in MSH6 and PMS2 carriers. ${ }^{37}$ Tailored surveillance based on transparent risk communication is aimed at early diagnostics, patient safety and rational use of resources. In the Danish Lynch syndrome cohort, $1.8 \%$ of CRCs were diagnosed under age 25 . Within this subgroup, $57.2 \%$ of the tumours were T3-T4, though only $21.3 \%$ were clinical stages III-IV (online supplemental table 1). International
Lynch syndrome surveillance programmes for CRC generally include biennial colonoscopies from age 20 to 25 years. ${ }^{30} 38$ In Denmark the recommended start age for colonoscopic surveillance is 25 years, which aligns with the start age recommended within the recent European guidelines. ${ }^{39}$ The youngest cases in our cohort were aged 15 and 18 years, respectively, at diagnosis. Information regarding CRC in the teenage period in Lynch syndrome is largely based on case reports, which precludes conclusions on genetic predictors and disease causes and implies that evidence for best practise is limited. ${ }^{40} 41$ The observation of early-onset CRC in patients with concomitant inflammatory bowel disease adds to a previously suggested increased risks and lower age at onset (median 36 years) in the $1.4 \%$ of Lynch syndrome individuals that have inflammatory bowel disease with a particularly increased risk for patients with ulcerative colitis. ${ }^{42-47}$ Suppression of low-grade inflammation by non-steroidal anti-inflammatory drugs could be particularly relevant in individuals with this dual risk profile. This is supported by preclinical data on synergistic effects from MMR deficiency and inflammation with an accelerated neoplastic process demonstrated in MSH2-deficient mice and from clinical observations of long-lasting effects from Aspirin demonstrated in the CAPP2 trial. $^{48-51}$ Denmark has a high and increasing incidence of inflammatory bowel disease, which implies that the diagnostic duality, Lynch syndrome and inflammatory bowel disease, is relevant from a cancer-prevention and early diagnostics perspective. $^{4252}$

In summary, $27.2 \%$ of the CRCs diagnosed in the Danish Lynch syndrome cohort developed under age $40 \%$ and $1.8 \%$ were diagnosed under age 25. CRCs under age 40 is linked to disease-predisposing alterations in MLH1 and $\mathrm{MSH} 2$ and show an adverse risk profile with more advanced stage tumours. In contrast, Lynch syndrome patients diagnosed with stage I-II tumours under age 40 , show a significantly better survival than the older age group. This underscores an unmet need for optimised clinical management to support early diagnostics in young individuals at increased risk of CRC. Furthermore, a possible link to inflammatory bowel disease is suggested in adolescents and young adults, which calls for attention to surveillance procedures and awareness of symptoms in individuals with dual risk profiles.

\section{CONCLUSION AND CLINICAL IMPLICATIONS}

Our investigation addresses early-onset CRC in a national Lynch syndrome cohort. We demonstrate that development of CRC in Lynch syndrome individuals under age 40 is largely driven by disease-predisposing variants in MLH1 and MSH2. This age group also shows a significant overrepresentation of T4 tumours and late-stage tumours which have implications for patient survival. Though being a rare presentation, we would like to stress awareness of early-onset CRC in order to optimise patient outcome. 
Twitter Jon Ambæk Durhuus @jondurhuus

Acknowledgements We would like to acknowledge Lars Smith Hansen for data extraction; the clinicians reporting patients and data to the Danish HNPCC register; the individuals working for the HNPCC register for their support; Susanne Manuela Germann for critical revision of the manuscript.

Contributors All contributors had full access to all data in this study and take responsibility for the integrity of the data and the accuracy of the data analysis. JAD is responsible for the overall content as guarantor. JAD, CT and MN were involved in study concept and design. JAD, CT and MN were involved in acquisition of data. TK was involved in statistical analysis. All authors contributed to data analysis and interpretation of data. JAD and MN were involved in drafting the manuscript. All authors were involved in critical revision of the manuscript. MN was involved in study supervision.

Funding This work was supported by the Danish Cancer Society grant number R204-A12599-B661.

Competing interests None declared.

Patient consent for publication Not applicable.

Ethics approval Registry studies are not subject to ethical review according to Danish regulations.

Provenance and peer review Not commissioned; externally peer reviewed.

Data availability statement Data are available upon reasonable request. Data are available from the authors upon request. Due to Danish legislation related to GDPR individual-level data are provided with a limited set of variables to preserve participants anonymity.

Supplemental material This content has been supplied by the author(s). It has not been vetted by BMJ Publishing Group Limited (BMJ) and may not have been peer-reviewed. Any opinions or recommendations discussed are solely those of the author(s) and are not endorsed by BMJ. BMJ disclaims all liability and responsibility arising from any reliance placed on the content. Where the content includes any translated material, BMJ does not warrant the accuracy and reliability of the translations (including but not limited to local regulations, clinical guidelines, terminology, drug names and drug dosages), and is not responsible for any error and/or omissions arising from translation and adaptation or otherwise.

Open access This is an open access article distributed in accordance with the Creative Commons Attribution Non Commercial (CC BY-NC 4.0) license, which permits others to distribute, remix, adapt, build upon this work non-commercially, and license their derivative works on different terms, provided the original work is properly cited, appropriate credit is given, any changes made indicated, and the use is non-commercial. See: http://creativecommons.org/licenses/by-nc/4.0/.

\section{ORCID iD}

Jon Ambæk Durhuus http://orcid.org/0000-0002-1274-5750

\section{REFERENCES}

1 Altobelli E, D'Aloisio F, Angeletti PM. Colorectal cancer screening in countries of European Council outside of the EU-28. World $\mathrm{J}$ Gastroenterol 2016;22:4946-57

2 Connell LC, Mota JM, Braghiroli MI, et al. The rising incidence of younger patients with colorectal cancer: questions about screening, biology, and treatment. Curr Treat Options Oncol 2017;18:23.

3 Saad El Din K, Loree JM, Sayre EC, et al. Trends in the epidemiology of young-onset colorectal cancer: a worldwide systematic review. BMC Cancer 2020;20:288.

4 Exarchakou A, Donaldson LJ, Girardi F, et al. Colorectal cancer incidence among young adults in England: trends by anatomical subsite and deprivation. PLoS One 2019;14:e0225547.

5 Jacobs D, Zhu R, Luo J, et al. Defining early-onset colon and rectal cancers. Front Oncol 2018;8:504.

6 Levine O, Zbuk K. Colorectal cancer in adolescents and young adults: defining a growing threat. Pediatr Blood Cancer 2019;66:e27941.

7 Malvezzi M, Carioli G, Bertuccio P, et al. European cancer mortality predictions for the year 2018 with focus on colorectal cancer. Ann Oncol 2018;29:1016-22.

8 Mauri G, Sartore-Bianchi A, Russo A-G, et al. Early-onset colorectal cancer in young individuals. Mol Oncol 2019;13:109-31.

9 Siegel RL, Fedewa SA, Anderson WF, et al. Colorectal cancer incidence patterns in the United States, 1974-2013. JNCI J Natl Cancer Inst 2017;109.
10 Siegel RL, Torre LA, Soerjomataram I, et al. Global patterns and trends in colorectal cancer incidence in young adults. Gut 2019;68:2179-85.

11 Troeung L, Sodhi-Berry N, Martini A, et al. Increasing incidence of colorectal cancer in adolescents and young adults aged 15-39 years in Western Australia 1982-2007: examination of colonoscopy history. Front Public Health 2017;5.

12 Yeo H, Betel D, Abelson JS, et al. Early-Onset colorectal cancer is distinct from traditional colorectal cancer. Clin Colorectal Cancer 2017;16:293-9.

13 Bailey CE, Hu C-Y, You YN, et al. Increasing disparities in the agerelated incidences of colon and rectal cancers in the United States, 1975-2010. JAMA Surg 2015;150:17-22.

14 Ballester V, Rashtak S, Boardman L. Clinical and molecular features of young-onset colorectal cancer. World J Gastroenterol 2016;22:22

15 Hampel H, Frankel WL, Martin E, et al. Feasibility of screening for Lynch syndrome among patients with colorectal cancer. J Clin Oncol 2008;26:5783-8.

16 Stoffel EM, Koeppe E, Everett J, et al. Germline genetic features of young individuals with Colorectal Cancer. Gastroenterology 2018;154:897-905

17 Chen FW, Sundaram V, Chew TA, et al. Advanced-Stage colorectal cancer in persons younger than 50 years not associated with longer duration of symptoms or time to diagnosis. Clin Gastroenterol Hepatol 2017;15:728-37.

18 Mork ME, You YN, Ying J, et al. High prevalence of hereditary cancer syndromes in adolescents and young adults with colorectal cancer. $J$ Clin Oncol 2015;33:3544-9.

19 Pearlman R, Frankel WL, Swanson B, et al. Prevalence and spectrum of germline cancer susceptibility gene mutations among patients with early-onset colorectal cancer. JAMA Oncol 2017;3:464.

20 Goshayeshi L, Ghaffarzadegan K, Khooei A, et al. Prevalence and clinicopathological characteristics of mismatch repair-deficient colorectal carcinoma in early onset cases as compared with lateonset cases: a retrospective cross-sectional study in northeastern Iran. BMJ Open 2018;8:e023102.

21 Jasperson KW, Tuohy TM, Neklason DW, et al. Hereditary and familial colon cancer. Gastroenterology 2010;138:2044-58.

22 Lynch HT, de la Chapelle A. Genetic susceptibility to non-polyposis colorectal cancer. J Med Genet 1999;36:801-18.

23 Bevan R, Rutter MD, Screening-Who CC. Colorectal cancer Screening-Who, how, and when? Clin Endosc 2018;51:37-49.

24 Menahem B, Alves A, Regimbeau JM, et al. Lynch syndrome: current management in 2019. J Visc Surg 2019;156:507-14.

25 Ramsey S, Whitley E, Mears VW, et al. Evaluating the costeffectiveness of cancer patient navigation programs: conceptual and practical issues. Cancer 2009;115:5394-403.

26 Hill DA, Furman WL, Billups CA, et al. Colorectal carcinoma in childhood and adolescence: a clinicopathologic review. J Clin Oncol 2007;25:5808-14.

27 Puccini A, Lenz H-J, Marshall JL, et al. Impact of patient age on molecular alterations of left-sided colorectal tumors. Oncologist 2019;24:319-26.

28 You YN, Lee LD, Deschner BW, et al. Colorectal cancer in the adolescent and young adult population. JCO Oncol Pract 2020;16:19-27.

29 Strum WB, Boland CR. Clinical and genetic characteristics of colorectal cancer in persons under 50 years of age: a review. Dig Dis Sci 2019;64:3059-65.

30 Lindberg LJ, Ladelund S, Frederiksen BL, et al. Outcome of 24 years national surveillance in different hereditary colorectal cancer subgroups leading to more individualised surveillance. J Med Genet 2017;54:297-304.

31 Huth C, Kloor M, Voigt AY, et al. The molecular basis of EpCAM expression loss in Lynch syndrome-associated tumors. Mod Pathol 2012;25:911-6.

32 von Elm E, Altman DG, Egger M, et al. Strengthening the reporting of observational studies in epidemiology (STROBE) statement: guidelines for reporting observational studies. BMJ 2007;335:806-8.

33 Wickham H. ggplot2: Elegant Graphics for Data Analysis. New York: Springer-Verlag, 2009.

34 Therneau TM. Survival: survival analysis, 2009. Available: https:// CRAN.R-project.org/package=survival

35 Dominguez-Valentin M, Seppälä TT, Sampson JR, et al. Survival by colon cancer stage and screening interval in Lynch syndrome: a prospective Lynch syndrome database report. Hered Cancer Clin Pract 2019;17:28.

36 Kessels K, Fidder HH, de Groot NL, et al. Adherence to microsatellite instability testing in young-onset colorectal cancer patients. Dis Colon Rectum 2013;56:825-33. 
37 Ryan NAJ, Morris J, Green K, et al. Association of mismatch repair mutation with age at cancer onset in Lynch syndrome. JAMA Oncol 2017;3:1702-6.

38 Biller LH, Syngal S, Yurgelun MB. Recent advances in Lynch syndrome. Fam Cancer 2019;18:211-9.

39 Seppälä TT, Latchford A, Negoi I, et al. European guidelines from the EHTG and ESCP for Lynch syndrome: an updated third edition of the Mallorca guidelines based on gene and gender. Br J Surg 2021;108:484-98.

40 Ahn $\mathrm{DH}$, Rho JH, Tchah $\mathrm{H}$, et al. Early onset of colorectal cancer in a 13-year-old girl with Lynch syndrome. Korean J Pediatr 2016;59:40-2.

41 Zajo K, Colace SI, Mouhlas D, et al. Lynch syndrome-associated colorectal cancer in a 16-year-old girl due to a de novo MSH2 mutation. BMJ Case Rep 2020;13:e233935.

42 Derikx LAAP, Smits LJT, van Vliet S, et al. Colorectal Cancer risk in patients with lynch syndrome and Inflammatory bowel disease. Clin Gastroenterol Hepatol 2017;15:454-8.

43 Drescher KM, Sharma P, Lynch HT. Current hypotheses on how microsatellite instability leads to enhanced survival of Lynch syndrome patients. Clin Dev Immunol 2010;2010:1-13.

44 Lourensz K, Jones I. Considerations and management of a patient with three metachronous cancers in association with Lynch syndrome and ileal Crohn's disease: a case report. Int J Surg Case Rep 2015;10:73-5.
45 Lynch HT, Lynch JF, Lynch PM, et al. Hereditary colorectal cancer syndromes: molecular genetics, genetic counseling, diagnosis and management. Fam Cancer 2008;7:27-39.

46 McNamara KL, Aronson MD, Cohen Z. Is there a role for prophylactic colectomy in Lynch syndrome patients with inflammatory bowel disease? Int J Colorectal Dis 2016;31:9-13.

47 Minami N, Yoshino T, Nakase H. Unique endoscopic findings of colitis-associated colorectal cancer in a patient with ulcerative colitis and Lynch syndrome. J Crohns Colitis 2014;8:336-7.

48 Kohonen-Corish MRJ, Daniel JJ, te Riele H, et al. Susceptibility of Msh2-deficient mice to inflammation-associated colorectal tumors. Cancer Res 2002;62:2092-7.

49 Stidham RW, Higgins PDR. Colorectal cancer in inflammatory bowel disease. Clin Colon Rectal Surg 2018;31:168-78.

50 Sankaranarayanan R, Kumar DR, Altinoz MA, et al. Mechanisms of colorectal cancer prevention by Aspirin-A literature review and perspective on the role of COX-Dependent and -independent pathways. Int J Mol Sci 2020;21:9018.

51 Burn J, Sheth H, Elliott F, et al. Cancer prevention with aspirin in hereditary colorectal cancer (Lynch syndrome), 10-year follow-up and registry-based 20-year data in the CAPP2 study: a double-blind, randomised, placebo-controlled trial. Lancet 2020;395:1855-63.

52 Liu X, Goldblum JR, Zhao Z, et al. Distinct clinicohistologic features of inflammatory bowel disease-associated colorectal adenocarcinoma: in comparison with sporadic microsatellite-stable and Lynch syndrome-related colorectal adenocarcinoma. Am J Surg Pathol 2012;36:1228-33. 